\title{
Kai Wantzen
}

\section{Unternehmenshaftung und Enterprise Liability}

Zur Idee unternehmensbezogener Schadenshaftung als Quasi-Versicherung

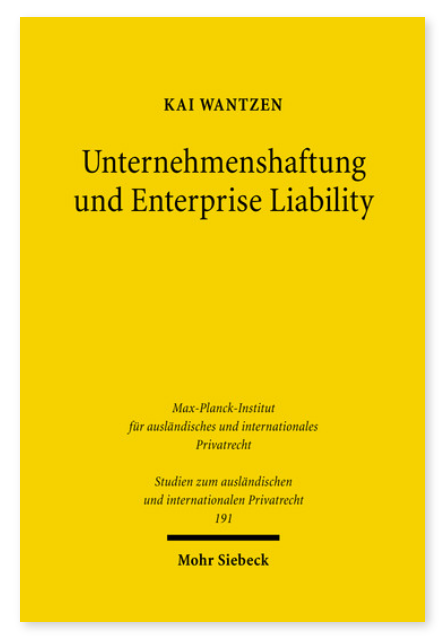

2007. XIII, 309 Seiten. StudIPR 191

ISBN 978-3-16-151376-3

DOI 10.1628/978-3-16-151376-3

eBook PDF 74,00€

ISBN 978-3-16-149422-2

fadengeheftete Broschur 74,00€
Enterprise Liability ist eines der schillernden Schlagwörter des US-amerikanischen Haftungsrechts nach dem Zweiten Weltkrieg. Es steht im Zentrum einer Bewegung, die sich zum Ziel gesetzt hatte, das Recht der außervertraglichen Haftung unter Betonung einer besonderen Haftungsverantwortlichkeit von Unternehmen zu einem Instrument der Wirtschafts- und Sozialpolitik zu entwickeln. Seit es Ende der 80er Jahre zu einer Haftpflichtversicherungskrise in den Vereinigten Staaten gekommen war, ist die Politik der Enterprise Liability auf dem Rückzug. Beides - also die Mobilisierung des Haftungsrechts für sozialpolitische Zwecke wie auch die Zurückdrängung des Haftungsrechts im Rahmen der jüngsten tort reforms - sind in Deutschland nicht unbemerkt geblieben. Auch in Deutschland wird das Schlagwort Enterprise Liability immer wieder aufgegriffen und auf die dem deutschen Recht eigenen Probleme der Unternehmenshaftung im Kontext der §§ 31, 831 BGB rückbezogen. Im europäischen Kontext hat Enterprise Liability ihren Niederschlag in der Produkthaftungsrichtlinie und den jüngsten Entwürfen im Rahmen der europäischen Deliktsrechtsvereinheitlichung gefunden. Kai Wantzen untersucht das Enterprise Liability Konzept, eine unternehmensbezogene Schadenstragung für Unfälle mit versicherungsähnlichen Zügen, das nach seinen Inhalten befragt wird und mit modernen Methoden der Haftungsrechtswissenschaft - der Rechtsvergleichung und der Rechtsökonomie - konfrontiert wird.

Kai Wantzen Geboren 1977; Studium der Rechtswissenschaft in Bonn und Leeds; 2003 LL.M. Washington University in St. Louis; Rechtsanwalt in Hamburg.

Jetzt bestellen:

https://mohrsiebeck.com/buch/unternehmenshaftung-und-enterprise-liability-9783161513763?no_cache=1 order@mohrsiebeck.com

Telefon: +49 (0)7071-923-17

Telefax: +49 (0)7071-51104 